\title{
SM Otolaryngology Independent Predictors of Malignancy in Patients with Multinodular Goiter
}

\author{
Mahmoud Sakr ${ }^{1}$, Heba Jaheen ${ }^{2}$, Essam Gabr ${ }^{1}$ and Ahmed Talha ${ }^{2}$ \\ ${ }^{1}$ Department of surgery, Head, Neck, and Endocrine Surgery Unit, Faculty of Medicine, University of \\ Alexandria, Egypt \\ ${ }^{2}$ Medical Research Institute, University of Alexandria, Egypt
}

\section{Article Information}

Received date: Nov 11, 2016

Accepted date: Jan 06, 2017

Published date: Jan 12, 2017

\section{*Corresponding author}

Mahmoud Sakr, Faulty of Medicine, University of Alexandria, Egypt, Tel: 002 01007834993;

Email: mah_sakr@yahoo.com

Distributed under Creative Commons CC-BY 4.0

Article DOI 10.36876/smotol.1001

\section{OPEN ACCESS}

ISSN: 2574-2418

\section{Abstract}

Introduction: Thyroid nodule is a common clinical finding. Ultrasound (US) and Fine-needle Aspiration (FNA) are the main methods used for investigating thyroid nodules, with questionable predictive values in Multinodular Goiter (MNG) compared to Solitary Thyroid Nodule (STN) due to the presence of multinodularity.

Objective: The present study was conducted to detect the independent predictors of malignancy in patients with MNG.

Patients \& Methods: Medical records of patients who were admitted for thyroidectomy at Alexandria Main University Hospital and Medical Research Institute Hospital between January 2013 and January 2016 were reviewed. Demographic and clinical data, US reports, FNA reports, and final histopathological results were recorded and analyzed by univariate and multivariate analysis. Patients with a STN, hyper- or hypo-thyroidism, previous history of surgery for thyroid cancer or those with incomplete data were excluded.

Results: Reports of 1014 patients were reviewed, 419 patients with euthyroid MNG were included in the study. Malignancy rate was $19.3 \%$ (81/419). Micro-calcification, solid consistency, ill-defined margins, and presence of suspicious cervical lymph nodes by US were statistically significant predictors. Rate of malignancy in Bethesda II was $8.9 \%$ (false negative). Malignant rate increased with increasing in Bethesda rating from Bethesda IV (17.4\%) to Bethesda V (51.7\%), and lastly Bethesda VI (90.9\%). Multivariate analysis revealed that micro-calcifications, suspicious cervical lymph nodes and Bethesda VI FNA were the independent predictors of malignancy. Other malignancy predictors that were only significant by univariate analysis were solid component of the nodule, and ill-defined margins.

Conclusion: Based on the data presented, it may be concluded that the independent predictors of malignancy in patients with MNG were US findings of micro-calcifications and suspicious cervical LNs as well as Bethesda VI on FNA.

\section{Introduction}

Thyroid nodules are a common clinical finding, with an estimated prevalence on the basis of palpation ranging from 3\%-7\% [1-3]. They are more common in the elderly, in women, in subjects with iodine deficiency, and in those with a history of radiation exposure [1].

The mean incidence of malignancy in thyroid nodules is $14 \%$ [4,5], which has been found to increase profoundly due to the wide application of high resolution Ultrasound (US) and FineNeedle Aspiration (FNA) [6,7]. Patients with Multinodular Goiter (MNG) have been reported to have the same risk of malignancy as those with Solitary Thyroid Nodule (STN) [8-10]. However, one large study reported that STN had a significantly higher likelihood for malignancy than MNG, although the risk of malignancy per patient was the same and independent of the number of nodules [11]. Diagnosis of MNG should rely on US examination since approximately $20 \%-48 \%$ of patients with one palpable thyroid nodule are found to have additional nodules on US [12,13].

The present retrospective study was carried out to detect the independent predictors of malignancy in patients with MNG.

\section{Patients and Methods}

\section{Study population}

All medical records of 1014 patients who were admitted to Alexandria Main University Hospital and Medical Research Institute Hospital, between January 2013 and January 2016, were retrospectively reviewed. After excluding patients with STN, hyper- or hypothyroidism, patients with incomplete recorded data, and those with a past history of thyroid malignancy (surgical thyroid biopsy for carcinoma), 419 patients who presented with euthyroid MNG (confirmed by US) and underwent thyroidectomy were included in the current study.

\section{Demographic and clinical data}

Age, gender, family history of thyroid cancer, previous history of irradiation or thyroid surgery, 
blood group, retrosternal extension, and clinical presentation were all reviewed.

\section{Imaging data}

The largest or the most suspicious nodule was evaluated in the reviewed reports regarding the following parameters; echogenicity, calcifications, halo (complete, incomplete), margins, consistency, vascularity, size (size was divided according to maximum diameter/ nodule into $<2 \mathrm{~cm}, 2-4 \mathrm{~cm},>4 \mathrm{~cm}$ ), presence of suspicious cervical Lymph Nodes (LNs) (rounded, $>0.5 \mathrm{~cm}$, lost hilum, peripheral vascularization, cystic changes, and calcification).

\section{Histopathological data}

The Bethesda system for reporting thyroid cytopathology (BIBVI) [4] was used, where BI is non-diagnostic or unsatisfactory, BII is benign, BIII means atypia or follicular lesion with undetermined significance, BIV is follicular neoplasm, BV is suspicious of malignancy and BVI is malignant. Predictive indices of FNA were calculated to detect the utility of (BVI) in diagnosing malignancy in MNG. All of the available data for each patient were compared to final histopathology.

\section{Statistical analysis}

Data were analyzed using IBM SPSS software package version 20.0 (Belmont, Calif 2013). Qualitative data were described using number and percent. Comparison between different groups regarding categorical variables was tested using Chi-square test When more than $20 \%$ of the cells have expected count less than 5 , correction for chi-square $\left(\chi^{2}\right)$ was conducted using Fisher's Exact test or Monte Carlo correction. Quantitative variables were presented as mean and standard deviation of the mean and were compared using the Student $t$ test. Agreement of the different predictive factors with the outcome was used and was expressed in sensitivity, specificity, Positive Predictive Value (PPV), Negative Predictive Value (NPV),

Table 1: Relation between US findings and thyroid malignancy $(n=387)$. and accuracy. Odd Ratio (OR) and 95\% Confidence Interval (CI) were used to calculate the ratio of the odds of an event occurring in one malignant group to the odds of it occurring in the benign group. Univariate and multivariate logistic regression were assessed. Significance of obtained results was judged at the $5 \%$ level.

\section{Results}

Out of 419 patients with MNG, 81 (19.3\%) were confirmed to have malignant disease by final histopathology. Thirteen out of 44 $(29.5 \%)$ male patients had malignancy, compared to $(18.1 \%, 68 / 375)$ female patients $\left(\chi^{2}=3.289, \mathrm{p} 0.07\right)$.

The mean age of the study population was $43.73 \pm 11.93$ years, with no statistically significant difference between the malignant and benign groups ( 43 years and 44 years, respectively). Likewise, when the population of study was divided into $\geq 45$ years and $<45$ years, no significant difference between both groups was found $\left(\chi^{2}=0.040\right.$, p 0.842).

Data of previous thyroid surgery were available in $95.2 \%$ (399/419) of patients, and showed that $8.6 \%$ of patients (3/35) with history of thyroid surgery had malignancy on final histopathology. Data of family history of thyroid cancer and previous radiation exposure were available in $94 \%$ of patients (394/419), and showed that all 11 patients with family history of thyroid malignancy were found to have benign disease on final pathologic results, and that the two patients who had history of radiation exposure turned out also to have benign disease.

The majority of patients (95.2\%) presented with a slowly progressive neck swelling with or without dyspnea and/or dysphagia not related to any other systemic disease. None of the patients presented with hoarseness of voice. Blood grouping results were available in $65.9 \%$ of patients $(276 / 419)$. The highest malignancy prevalence was seen in A-patients (25\%), followed by $\mathrm{O}+$ patients (18.9\%) and $A+$ patients (17.3\%). However, the difference was not statistically significance $\left(\chi^{2}=4.99, \mathrm{P} 0.599\right)$.

\begin{tabular}{|c|c|c|c|c|c|c|c|c|c|}
\hline & \multicolumn{4}{|c|}{ Pathology } & \multirow{3}{*}{ Sensitivity } & \multirow{3}{*}{ Specificity } & \multirow{3}{*}{ PPV } & \multirow{3}{*}{ NPV } & \multirow{3}{*}{ Accuracy } \\
\hline & \multicolumn{2}{|c|}{$\begin{array}{l}\text { Benign } \\
(n=320)\end{array}$} & \multicolumn{2}{|c|}{$\begin{array}{l}\text { Malignant } \\
\qquad(n=67)\end{array}$} & & & & & \\
\hline & $\mathrm{n}$ & $\%$ & $\mathbf{n}$ & $\%$ & & & & & \\
\hline Hypoechoic(n=111) & & & & & \multirow{4}{*}{35.82} & \multirow{4}{*}{73.13} & \multirow{4}{*}{21.82} & \multirow{4}{*}{84.48} & \multirow{4}{*}{66.67} \\
\hline -ve $(n=277)$ & 234 & 84.5 & 43 & 15.5 & & & & & \\
\hline +ve $(n=111)$ & 87 & 78.2 & 24 & 21.8 & & & & & \\
\hline$X^{2}(p)$ & \multicolumn{4}{|c|}{$2.179(0.140)$} & & & & & \\
\hline Microcalcifications $(n=29)$ & & & & & \multirow{4}{*}{19.40} & \multirow{4}{*}{95.0} & \multirow{4}{*}{44.83} & \multirow{4}{*}{84.92} & \multirow{4}{*}{81.91} \\
\hline -ve $(n=358)$ & 304 & 84.9 & 54 & 15.1 & & & & & \\
\hline$+v e(n=29)$ & 16 & 55.2 & 13 & 44.8 & & & & & \\
\hline$X^{2}(p)$ & \multicolumn{4}{|c|}{$16.579^{*}\left(<0.001^{\star}\right)$} & & & & & \\
\hline Solid (n=28) & & & & & \multirow{4}{*}{14.93} & \multirow{4}{*}{94.38} & \multirow{4}{*}{35.7} & \multirow{4}{*}{81.12} & \multirow{4}{*}{80.62} \\
\hline -ve $(n=359)$ & 302 & 84.1 & 57 & 15.9 & & & & & \\
\hline$+v e(n=28)$ & 18 & 64.3 & 10 & 35.7 & & & & & \\
\hline $\mathrm{X}^{2}\left(\mathrm{FE}_{\mathrm{p}}\right)$ & \multicolumn{4}{|c|}{$7.140^{*}\left(0.016^{*}\right)$} & & & & & \\
\hline Incomplete halo $(\mathrm{n}=2)$ & & & & & \multirow{4}{*}{2.99} & \multirow{4}{*}{100.0} & \multirow{4}{*}{100.0} & \multirow{4}{*}{83.12} & \multirow{4}{*}{83.20} \\
\hline$-v e(n=385)$ & 320 & 83.1 & 65 & 16.9 & & & & & \\
\hline$+v e(n=2)$ & 0 & 0.0 & 2 & 100.0 & & & & & \\
\hline $\mathrm{X}^{2}\left(\mathrm{FE}^{\mathrm{p}} \mathrm{p}\right)$ & & 9.602 & $.030^{\prime}$ & & & & & & \\
\hline Ill-defined margin $(n=372)$ & & & & & & & & & \\
\hline -ve $(n=372)$ & 311 & 83.6 & 61 & 16.4 & 896 & 9719 & 400 & 8360 & 819 \\
\hline$+v e(n=15)$ & 9 & 60.0 & 6 & 40.0 & 8.96 & 97.19 & 40.0 & 83.60 & 81.9 \\
\hline $\mathrm{X}^{2}\left({ }^{\mathrm{FE}} \mathrm{p}\right)$ & & 5.611 & $.030^{\prime}$ & & & & & & \\
\hline Intra-nodular vascularity $(n=13)$ & & & & & & & & & \\
\hline -ve $(n=374)$ & 312 & 83.4 & 62 & 16.6 & 7.46 & 9750 & 385 & 83.42 & 819 \\
\hline$+v e(n=13)$ & 8 & 61.5 & 5 & 38.5 & 7.46 & 97.50 & 38.5 & 83.42 & 81.9 \\
\hline $\mathrm{X}^{2}(\mathrm{FE} \mathrm{p})$ & & 4.203 & 0.056 & & & & & & \\
\hline
\end{tabular}

$\chi^{2}$ : Chi square test

FE: Fisher Exact test*: Statistically significant at $p \leq 0.05$ 
Table 2: Fine-Needle Aspiration (FNA) Biopsy as a diagnostic test for thyroid malignancy $(n=361)$.

\begin{tabular}{|c|c|c|c|c|c|c|c|c|c|c|}
\hline \multirow[b]{3}{*}{$\begin{array}{l}\text { FNA }(\mathbf{n = 3 6 1 )} \\
\text { Bethesda Classification }\end{array}$} & \multicolumn{4}{|c|}{ Pathology } & \multirow{3}{*}{$\begin{array}{l}\text { Odds Ratio } \\
\text { (95\%LL-UL) }\end{array}$} & \multirow[b]{3}{*}{ Sensitivity } & \multirow[b]{3}{*}{ Specificity } & \multirow[b]{3}{*}{ PPV } & \multirow[b]{3}{*}{ NPV } & \multirow[b]{3}{*}{ Accuracy } \\
\hline & \multicolumn{2}{|c|}{ Benign } & \multicolumn{2}{|c|}{ Malignant } & & & & & & \\
\hline & $\mathbf{n}$ & $\%$ & $\mathbf{n}$ & $\%$ & & & & & & \\
\hline $\begin{array}{l}-\mathrm{ve}(\mathrm{II}-\mathrm{V}) \\
\quad(\mathrm{n}=350)\end{array}$ & 292 & 83.4 & 58 & 16.6 & \multirow{4}{*}{$\begin{array}{c}50.345 \\
(6.322-400.91)\end{array}$} & \multirow{4}{*}{14.7} & \multirow{4}{*}{99.7} & \multirow{4}{*}{90.9} & \multirow{4}{*}{83.4} & \multirow{4}{*}{83.7} \\
\hline $\begin{array}{l}+ \text { ve }(\mathrm{VI}) \\
\qquad(\mathrm{n}=11)\end{array}$ & 1 & 9.1 & 10 & 90.9 & & & & & & \\
\hline Total $(n=361)$ & 293 & 81.2 & 68 & 18.8 & & & & & & \\
\hline$x^{2}(p)$ & \multicolumn{4}{|c|}{$38.549^{*}\left(<0.001^{*}\right)$} & & & & & & \\
\hline
\end{tabular}

$X^{2}$ : Chi square test *: Statistically significant at $p \leq 0.05$.

Table 3: Multivariate analysis logistic regression of predictors of thyroid malignancy.

\begin{tabular}{|c|c|c|c|c|c|c|c|}
\hline & & \multirow{2}{*}{ B } & \multirow{2}{*}{ SE } & \multirow{2}{*}{$P$ value } & \multirow{2}{*}{ Odds Ratio } & \multicolumn{2}{|c|}{$95.0 \% \mathrm{Cl}$} \\
\hline & & & & & & Lower & Upper \\
\hline- & Microcalcification & 1.452 & 0.453 & $0.001^{*}$ & 4.270 & 1.758 & 10.374 \\
\hline- & FNA (B VI) & 3.079 & 1.189 & $0.010^{*}$ & 21.736 & 2.114 & 223.491 \\
\hline- & Suspicious cervical LN (US) & 1.538 & 0.599 & $0.010^{*}$ & 4.655 & 1.438 & 15.072 \\
\hline- & III-defined margin (US) & 1.056 & 0.64 & 0.099 & 2.876 & 0.82 & 10.088 \\
\hline- & Solid (US) & 0.794 & 0.495 & 0.108 & 2.212 & 0.839 & 5.832 \\
\hline- & Intra-nodular vascularity (US) & 0.909 & 0.713 & 0.202 & 2.481 & 0.613 & 10.035 \\
\hline
\end{tabular}

Ultrasound reports were available in $92.4 \%$ of the reviewed records (387/419); of those, 67 patients (17.3\%) were found to have malignancy. Ultrasound features were summarized in Table 1. As may be seen, statistically significant US features included microcalcifications, solid nodules, echogenicity, incomplete halo, and ill-defined margins. Ultrasonographic reports regarding Cervical Lymph Nodes (LNs) were available in $92.4 \%$ of patients (387/419). Eleven (52.4\%) patients out of 21 with suspicious cervical LNs proved to be malignant $\left(\chi^{2}=19.09, \mathrm{p}<0.001\right)$.

Nodule size was reported sonographically for 325 out of 387 nodules (84\%). Although, largest nodules $(>4 \mathrm{~cm})$ had the highest rate of malignancy $(21.3 \%)$, yet, there was no statistically significant difference regarding nodule size and occurrence of malignancy $\left(\chi^{2}=0.894, \mathrm{p}=0.599\right)$. There was no statistically significant difference in

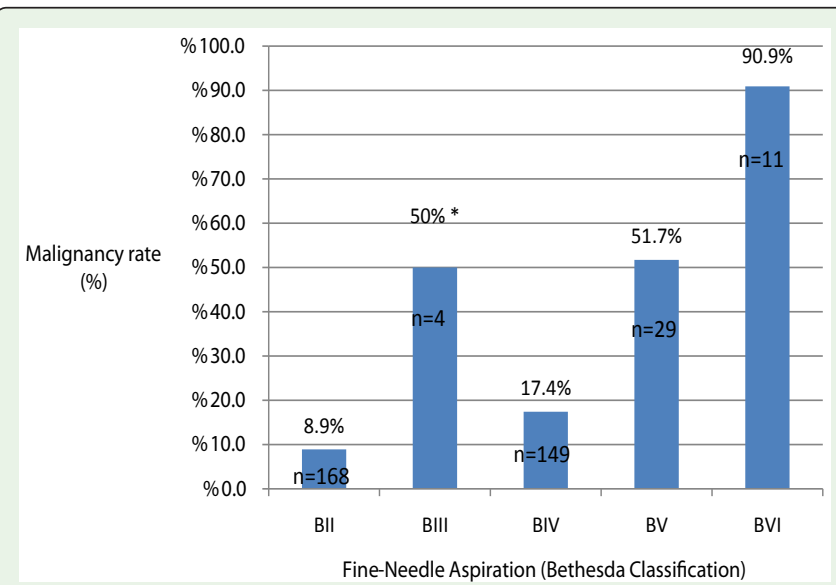

Figure 1: Relation between incidence of malignancy and FNA (Bethesda System). malignancy occurrence between patients with retrosternal extension as detected by CT scan (20\%) and those without $(16.4 \%)\left(\chi^{2}=0.30\right.$, $\mathrm{p}=0.58)$.

Reports of FNA were found in the reviewed records of 370 (88.3\%) patients, of whom 71 (19.2\%) lesions were found to be malignant on final histopathological examination. As seen in Table 2, the collective reports of BII-BV (non-malignant) revealed that $16.6 \%$ turned out to be malignant on final histopathology. Regarding patients who were BII (benign), 8.9\% were false negative. On the other hand, BVI (malignant), showed one false positive case (1/11, 9.1\%), and a PPV of $90.9 \%$. The correlation between Bethesda Classification and thyroid malignancy is shown in Figure 1. As may be seen, the difference between the benign and malignant thyroid disease was highly significant for BV and BVI, and was highly protective against cancer for BII.

Multivariate analysis of predictors of malignancy is summarized in Table 3. The highest predictor was microcalcifications, followed by FNA (BVI), presence of suspicious cervical LNs, and lastly echogenicity.

\section{Discussion}

The clinical importance of thyroid nodules rests with the need to exclude thyroid cancer, which occurs in $5-15 \%$ of cases depending on age, sex, radiation exposure, family history of thyroid malignancy, other associated syndromes, and other factors [2,8,14-16].

In the current retrospective study, $19.3 \%$ of patients (81/419) with MNG were found to have malignant disease on final histopathology. Similar results were reported by other authors, with a malignancy rate ranging from $5.7 \%$ to $31 \%$, and an average of $1 \%-14 \%$ [2,11,15,17-22]. On the other hand, malignancy rate of STN was reported by McCall et al. [23] to be $17 \%$ (i.e. close to that of MNG). The difference in 
the reported rates of malignancy among patients with MNG in the above studies undoubtedly reflects difference in the selection criteria used for analysis, as well as geographic differences in the population studied [19].

In the present study, no significant difference in age was found between patients with benign disease and those with malignant disease. The median age was 44 years and 43 years, respectively. Men had a higher malignancy rate $(29.5 \%)$ than women (18.1\%), but the difference was not statistically significant. In a study by Luo et al. (15), age lost its significance as an independent risk factor for thyroid malignancy when included in a multivariate analysis, suggesting that age is not an independent risk factor for malignancy and will likely not be helpful in predicting the risk of malignancy in a given patient. In 2008, Salmaslioglu et al. [20], reported that detection of malignancy did not correlate with patient's age or gender, which is in accordance with the current findings. Other studies however, showed that the rates of thyroid carcinoma on final pathologic evaluation were statistically higher in older male patients $[11,24]$. It is conceivable that correlating age and gender, and the incidence of malignancy in MNG patients, is widely contradicting; probably due to difference in patients selection and numbers of the study population $[1,8,11,25]$.

History of previous radiation exposure and presence of family history of thyroid cancer are well established risk factors that even affect the decision for FNA biopsy of thyroid nodule more than the nodule size itself $[1,8,10,26,27]$. Significant difference could not be detected in the present study regarding family history of thyroid cancer, previous radiation exposure, or even history of previous thyroid surgery. This may be attributed to incomplete or inaccurate data of patients' records in the present retrospective study.

Combining high resolution US with FNA in evaluating thyroid nodules is considered the modality of choice in investigating nodular thyroid gland $[1,28]$. Out of the analyzed US features in this study, microcalcification was an independent risk factor with the highest Odds ratio, followed by ill-defined margins and then solid consistency of thyroid nodules. In the current study, microcalcification had high specificity of $95 \%$. Similar results were reported by other studies that investigated the risk of malignancy in MNG alone [20,29-32], or in both MNG and STN [29, 33-37].

Ill-defined irregular margins on US had a high specificity of $97.19 \%$, albeit with a very low sensitivity of $8.9 \%$. Other studies reported a wide range of sensitivity (7\%-97\%) [20,38] and a variable specificity, with $15 \%-59 \%$ of benign nodules having poorly defined margins [10,20,39]. The AACE (American Association of Clinical Endocrinology) Guidelines reported specificity of ill-defined irregular margins to range from $48 \%-91.8 \%$ [1]. In the present study, the rate of ill-defined margins was greater in malignant nodules than in benign ones $(8.95 \%-2.81 \%$, respectively).

Similar to our findings, Salmaslioglu et al. [20] reported that nodules with solid component were significantly associated with malignancy in patients with MNG. However, intra-nodular hypervascularity, contrary to the reports of other studies $[8,35,36]$ was not statistically significant in patients with malignancy as compared to those with benign disease.

Hypo-echogencity was the most presenting US feature in the present study $(\mathrm{n}=111)$, being non-significantly higher in malignant nodules. More than three quarters (78\%) of hypoechoic nodules were found to be benign. Similarly, Panini et al. [10] reported that 55\% of benign nodules were hypoechoic. Moreover, most non-palpable thyroid nodules were reported to be hypoechoic and benign [20,33]. Thus, hypo-echogencity seems to have a very poor predictive value when interpreted alone to predict malignancy [33]. On the other hand, another study showed significant difference in hypoechoic appearance between benign and malignant nodules [20].

Cytopathological examination is the corner stone in appraising the malignant potential of a given thyroid nodule. A meta-analysis study reported non-diagnostic incidence rate between $1.8 \%$ and $23.6 \%$, with a collectively reported malignancy rate of $16.8 \%$ [6]. In the current study, 9 (2.3\%) patients were classified as Bethesda I with a malignancy rate of $33 \%(3 / 9)$. This high rate could be attributed to several factors; not all FNA in the present study were obtained under US guidance, no on-site smear adequacy assessment was adopted, not all reviewed FNA reports were performed by same pathologist, and most of biopsied nodules were large in size $(\geq 4 \mathrm{~cm})$, which is associated with a high malignancy rate, reaching $27 \%$ as reported by Pinchot et al. [24] and Gharib et al. [1]. In this study, 8.4\% of Bethesda II patients had false negative results (i.e. malignant disease). The false negative rate of $0-8 \%$ were reported by several authors $[6,8,17,40,41]$, with the rate being higher in large nodules $(\geq 4 \mathrm{~cm})[8,24,42]$.

The rate of malignancy increases with increasing in Bethesda rating from Bethesda IV (17.4\%) to Bethesda V (51.7\%), and lastly, Bethesda VI (90.9\%). The average of reported rate of malignancy in the literature ranged from $1.2 \%-25.3 \%$ for Bethesda IV [4,6,17,43-45], from $60 \%-75 \%$ for Bethesda V $[4,6,46,47]$, and from $97 \%-99 \%$ for Bethesda VI $[4,8]$. Ideally, false positive cases in Bethesda VI reports should be less than $1 \%$, ranging from $0.5 \%-10 \%$ [17,48-50]. Similar to the presented results, the PPV of Bethesda VI in MNG ranged between $50 \%$ and $96 \%$ [17].

Based on the data presented, it may be concluded that [1] the most significant independent predictors of malignancy in patients with MNG are microcalcifications, suspicious cervical LNs by US, and FNA (Bethesda VI), and [2] other malignant predictors include solid component of the nodule, and ill-defined margins but are only significant on univariate analysis. Comparison between the predictors of malignancy between MNG and STN merits further studies and is currently being investigated.

\section{References}

1. Gharib H, Papini E, Paschke R, Duick DS, Valcavi R, Hegedus L, et al. American Association of Clinical Endocrinologists, Associazione Medici Endocrinologi, and European Thyroid Association medical guidelines for clinical practice for the diagnosis and management of thyroid nodules: executive summary of recommendations. J Endocrinol Invest. 2010; 33: 5156.

2. Hegedus L. Clinical practice. The thyroid nodule. N Engl J Med. 2004; 351: 1764-1771.

3. Maddox P, Wheeler M. approach to thyroid nodules. In: Clark $\mathrm{OH}$, Duh QY, Kebebew E, editors. Textbook of Endocrine Surgery: W.B. Saunders. 2005; 85.

4. Cibas ES, Ali SZ. The Bethesda System for Reporting Thyroid Cytopathology. Am J Clin Pathol. 2009; 132: 658-665.

5. Hamberger B, Gharib H, Melton LJ 3rd, Goellner JR, Zinsmeister AR. Fineneedle aspiration biopsy of thyroid nodules. Impact on thyroid practice and cost of care. Am J Med. 1982; 73: 381-384 
6. Bongiovanni M, Spitale A, Faquin WC, Mazzucchelli L, Baloch ZW. The Bethesda System for Reporting Thyroid Cytopathology: a meta-analysis. Acta Cytol. 2012; 56: 333-339.

7. Yassa L, Cibas ES, Benson CB, Frates MC, Doubilet PM, Gawande AA, et al. Long-term assessment of a multidisciplinary approach to thyroid nodule diagnostic evaluation. Cancer. 2007; 111: 508-516.

8. Cooper DS, Doherty GM, Haugen BR, Kloos RT, Lee SL, Mandel SJ, et al Revised American Thyroid Association management guidelines for patients with thyroid nodules and differentiated thyroid cancer. Thyroid. 2009; 19 : 1167-1214.

9. Marqusee E, Benson CB, Frates MC, Doubilet PM, Larsen PR, Cibas ES, et al. Usefulness of ultrasonography in the management of nodular thyroid disease. Ann Intern Med. 2000; 133: 696-700.

10. Papini E, Guglielmi R, Bianchini A, Crescenzi A, Taccogna S, Nardi F, et al. Risk of malignancy in nonpalpable thyroid nodules: predictive value of ultrasound and color-Doppler features. J Clin Endocrinol Metab. 2002; 87: 1941-1946.

11. Frates MC, Benson CB, Doubilet PM, Kunreuther E, Contreras M, Cibas ES, et al. Prevalence and distribution of carcinoma in patients with solitary and multiple thyroid nodules on sonography. J Clin Endocrinol Metab. 2006; 91 3411-3417.

12. Ezzat S, Sarti DA, Cain DR, Braunstein GD. Thyroid incidentalomas Prevalence by palpation and ultrasonography. Arch Intern Med. 1994; 154 1838-1840.

13. Tan GH, Gharib H. Thyroid incidentalomas: management approaches to nonpalpable nodules discovered incidentally on thyroid imaging. Ann Intern Med. 1997; 126: 226-231.

14. Mandel SJ. A 64-year-old woman with a thyroid nodule. JAMA. 2004; 292 2632-2642.

15. Luo J, McManus C, Chen H, Sippel RS. Are there predictors of malignancy in patients with multinodular goiter? J Surg Res. 2012; 174: 207-210.

16. Pinchera A, Aghini-Lombardi $F$, Antonangeli L, Vitti $P$. Multinodular goiter Epidemiology and prevention. Ann Ital Chir. 1996; 67: 317-325.

17. Rios A, Rodriguez JM, Galindo PJ, Montoya M, Tebar FJ, Sola J, et al Utility of fine-needle aspiration for diagnosis of carcinoma associated with multinodular goitre. Clin Endocrinol (Oxf). 2004; 61: 732-737.

18. Acioglu E, Yigit O, Seden N, Huq GE. The predictive value of dominant nodules and the management of indeterminate group in multinodular goiter Eur Arch Otorhinolaryngol. 2012; 269: 283-287.

19. Tollin SR, Mery GM, Jelveh N, Fallon EF, Mikhail M, Blumenfeld W, et al. The use of fine-needle aspiration biopsy under ultrasound guidance to assess the risk of malignancy in patients with a multinodular goiter. Thyroid. 2000 10: $235-241$.

20. Salmaslioglu A, Erbil Y, Dural C, Issever H, Kapran Y, Ozarmagan S, et al. Predictive value of sonographic features in preoperative evaluation of malignant thyroid nodules in a multinodular goiter. World J Surg. 2008; 32 1948-1954.

21. Sachmechi I, Miller E, Varatharajah R, Chernys A, Carroll Z, Kissin E, et al. Thyroid carcinoma in single cold nodules and in cold nodules of multinodular goiters. Endocr Pract. 2000; 6: 5-7.

22. Bonnema SJ, Bennedbaek FN, Ladenson PW, Hegedus L. Management of the nontoxic multinodular goiter: a North American survey. J Clin Endocrino Metab. 2002; 87: 112-117.

23. McCall A, Jarosz H, Lawrence AM, Paloyan E. The incidence of thyroid carcinoma in solitary cold nodules and in multinodular goiters. Surgery. 1986; 100: 1128-1132

24. Pinchot SN, Al-Wagih H, Schaefer S, Sippel R, Chen H. Accuracy of fineneedle aspiration biopsy for predicting neoplasm or carcinoma in thyroid nodules $4 \mathrm{~cm}$ or larger. Arch Surg. 2009; 144: 649-655.
25. Corrias A, Einaudi S, Chiorboli E, Weber G, Crino A, Andreo M, et al. Accuracy of fine needle aspiration biopsy of thyroid nodules in detecting malignancy in childhood: comparison with conventional clinical, laboratory, and imaging approaches. J Clin Endocrinol Metab. 2001; 86: 4644-4648.

26. Rosenbaum MA, McHenry CR. Contemporary management of papillary carcinoma of the thyroid gland. Expert Rev Anticancer Ther. 2009; 9: 317329.

27. Punales MK, da Rocha AP, Meotti C, Gross JL, Maia AL. Clinical and oncological features of children and young adults with multiple endocrine neoplasia type 2A. Thyroid. 2008; 18: 1261-1268.

28. Jo VY, Stelow EB, Dustin SM, Hanley KZ. Malignancy risk for fine-needle aspiration of thyroid lesions according to the Bethesda System for Reporting Thyroid Cytopathology. Am J Clin Pathol. 2010; 134: 450-456.

29. Frates MC, Benson CB, Charboneau JW, Cibas ES, Clark OH, Coleman BG, et al. Management of thyroid nodules detected at US: Society of Radiologists in Ultrasound consensus conference statement. Radiology. 2005; 237: 794 800.

30. Khoo ML, Asa SL, Witterick IJ, Freeman JL. Thyroid calcification and its association with thyroid carcinoma. Head Neck. 2002; 24: 651-655.

31. Chan BK, Desser TS, McDougall IR, Weigel RJ, Jeffrey RB Jr. Common and uncommon sonographic features of papillary thyroid carcinoma. J Ultrasound Med. 2003; 22: 1083-1090.

32. Cappelli C, Castellano M, Pirola I, Cumetti D, Agosti B, Gandossi E, et al. The predictive value of ultrasound findings in the management of thyroid nodules. QJM. 2007; 100: 29-35.

33. Hoang JK, Lee WK, Lee M, Johnson D, Farrell S. US Features of thyroid malignancy: pearls and pitfalls. Radiographics. 2007; 27: 847-865.

34. Kim EK, Park CS, Chung WY, Oh KK, Kim DI, Lee JT, et al. New sonographic criteria for recommending fine-needle aspiration biopsy of nonpalpable solid nodules of the thyroid. AJR Am J Roentgenol. 2002; 178: 687-691.

35. Mandel SJ. Diagnostic use of ultrasonography in patients with nodular thyroid disease. Endocr Pract. 2004; 10: 246-252.

36. Moon WJ, Jung SL, Lee JH, Na DG, Baek JH, Lee YH, et al. Benign and malignant thyroid nodules: US differentiation--multicenter retrospective study. Radiology. 2008; 247: 762-770.

37. Iannuccilli JD, Cronan JJ, Monchik JM. Risk for malignancy of thyroid nodules as assessed by sonographic criteria: the need for biopsy. J Ultrasound Med. 2004; 23: 1455-1464

38. Lu C, Chang TC, Hsiao YL, Kuo MS. Ultrasonographic findings of papillary thyroid carcinoma and their relation to pathologic changes. J Formos Med Assoc. 1994; 93: 933-938

39. Wienke JR, Chong WK, Fielding JR, Zou KH, Mittelstaedt CA. Sonographic features of benign thyroid nodules: interobserver reliability and overlap with malignancy. J Ultrasound Med. 2003; 22: 1027-1031.

40. Bombil I, Bentley A, Kruger D, Luvhengo TE. Incidental cancer in multinodular goitre post thyroidectomy. S Afr J Surg. 2014; 52: 5-9.

41. Ylagan LR, Farkas T, Dehner LP. Fine needle aspiration of the thyroid: a cytohistologic correlation and study of discrepant cases. Thyroid. 2004; 14 $35-41$.

42. McCoy KL, Jabbour N, Ogilvie JB, Ohori NP, Carty SE, Yim JH. The incidence of cancer and rate of false-negative cytology in thyroid nodules greater than or equal to $4 \mathrm{~cm}$ in size. Surgery. 2007; 142: 837-844.

43. Yang J, Schnadig V, Logrono R, Wasserman PG. Fine-needle aspiration of thyroid nodules: a study of 4703 patients with histologic and clinical correlations. Cancer. 2007; 111: 306-315.

44. Deveci MS, Deveci G, LiVolsi VA, Baloch ZW. Fine-needle aspiration of follicular lesions of the thyroid. Diagnosis and follow-Up. Cytojournal. 2006; 3: 9 . 
45. Baloch ZW, Fleisher S, LiVolsi VA, Gupta PK. Diagnosis of "follicular neoplasm": a gray zone in thyroid fine-needle aspiration cytology. Diagn Cytopathol. 2002; 26: 41-44.

46. Wu HH, Rose C, Elsheikh TM. The Bethesda system for reporting thyroid cytopathology: An experience of 1,382 cases in a community practice setting with the implication for risk of neoplasm and risk of malignancy. Diagn Cytopathol. 2012; 40: 399-403.

47. Theoharis CG, Schofield KM, Hammers L, Udelsman R, Chhieng DC. The Bethesda thyroid fine-needle aspiration classification system: year 1 at an academic institution. Thyroid. 2009; 19: 1215-1223.
48. Poller DN, Ibrahim AK, Cummings MH, Mikel JJ, Boote D, Perry M. Fineneedle aspiration of the thyroid. Cancer. 2000; 90: 239-244.

49. Tuttle RM, Lemar H, Burch HB. Clinical features associated with an increased risk of thyroid malignancy in patients with follicular neoplasia by fine-needle aspiration. Thyroid. 1998; 8: 377-383.

50. Davoudi MM, Yeh KA, Wei JP. Utility of fine-needle aspiration cytology and frozen-section examination in the operative management of thyroid nodules. Am Surg. 1997; 63: 1084-1090. 